\title{
Impacts of COVID-19 Lockdown on Food Ordering Patterns among Youths in China: The COVID-19 Impact on Lifestyle Change Survey
}

\author{
Shujuan Yang ${ }^{\mathrm{a}, \mathrm{e}}$ Hui Chen ${ }^{\mathrm{b}, \mathrm{c}}$ Jialong Wu ${ }^{\mathrm{a}}$ Bing Guo $^{\mathrm{a}}$ Junmin Zhou ${ }^{\mathrm{a}}$ \\ Changzheng Yuan ${ }^{c}$ Peng Jiad, e \\ ${ }^{a}$ West China School of Public Health and West China Fourth Hospital, Sichuan University, Chengdu, China; ${ }^{b}$ College \\ of Biosystems Engineering and Food Science, Zhejiang University, Hangzhou, China; 'The Children's Hospital \\ and School of Public Health, Zhejiang University School of Medicine, Hangzhou, China; ${ }^{d}$ School of Resource \\ and Environmental Sciences, Wuhan University, Wuhan, China; eInternational Institute of Spatial Lifecourse \\ Epidemiology (ISLE), Wuhan University, Wuhan, China
}

\section{Keywords}

COVID-19 $\cdot$ Obesity $\cdot$ Food ordering $\cdot$ Youth $\cdot$ Lockdown

\begin{abstract}
Introduction: Limited studies have focused on how the COVID-19 outbreak and thereby lockdown had affected the youth's food ordering patterns, which was associated with their dietary behaviors and could have longer term impacts on their later-life health status if the trend persists. This study aimed to evaluate changes in food ordering patterns among youths in China after the COVID-19 outbreak. Methods: The data were obtained from a national retrospective survey (COINLICS) conducted in early May 2020 via social media platforms in China among more than 10,000 youth participants at 3 educational levels. Participants reported their basic sociodemographic characteristics, weight status, and lifestyles including food ordering patterns. We described and compared their weight status and food ordering patterns before COVID-19 (January) and under lockdown (February). Results: We observed significant changes in youths' weight status and food ordering patterns under lockdown. A significant increase was observed in the prevalence of over-
\end{abstract}

karger@karger.com www.karger.com/ofa

Karger"

BOPEN ACCESS
(C) 2022 The Author(s)

Published by S. Karger AG, Basel

This is an Open Access article licensed under the Creative Commons Attribution-NonCommercial-4.0 International License (CC BY-NC) (http://www.karger.com/Services/OpenAccessLicense), applicable to the online version of the article only. Usage and distribution for commercial purposes requires written permission. weight/obesity (13.5\%-17.0\%) and obesity (8.7-10.8\%), which varied by sex and educational level. Overall, the average weekly frequency of food ordering among the Chinese students had declined, with the largest decrease seen among graduate students, followed by undergraduate and high/vocational school students. Regardless of types of food, the percentage of participating youths who started ordering under lockdown was all lower than that of youths who stopped ordering. Among those who had still ordered foods under lockdown, a larger percentage of female than male high/vocational school students ordered barbecue/grill and cakes/ pastries; no significant differences were found across the educational levels. Conclusion: The participating youths' food ordering patterns had significantly changed during the COVID-19 lockdown, with heterogeneities observed to different extents between sexes and across educational levels. Our findings would inform policy makers and health professionals of these changes in time, for better policy making and public health practice.

(C) 2022 The Author(s)

Published by S. Karger AG, Basel

Shujuan Yang and Hui Chen equal contribution.
Correspondence to:

Changzheng Yuan, chy478@zju.edu.cn

Peng Jia, jiapengff@ hotmail.com 


\section{Introduction}

In recent years, the food ordering industry (e.g., takeout industry) in China has developed rapidly. The market scale of online-to-offline food industry increased from USD 3.4 billion in 2011 to USD 32.5 billion in 2017, and the customers of such industry increased from 114 million in 2015 to 343 million in 2017 in China, which was more than $1 / 5$ of the Chinese population $[1,2]$. Food ordering has become routine for many Chinese young people, among whom white-collar workers and college students have become the main consumers of the online food ordering platforms [1]. The growing trend of food ordering offers great opportunities for improving food accessibility and accommodation in China while, on the other hand, posing inevitable challenges to the whole public health system and social environment in China [2, 3].

An increased amount of attention has been paid to the influence of food ordering patterns in the field of public nutrition [4-6]. The Nutritional Analysis on Internet Catering Consumption (2018), released by the China Nutrition Society, has shown that online ordering of fried food, spicy food, and meat is on the high side, while ordering of vegetables, soybean products, and aquatic products is relatively low. One study showed that among the personal and lifestyle characteristics, a high consumption of ordered food was significantly associated with a high preference for high-fat-high-sugar food and a higher body mass index (BMI) [7]. Other studies showed that the consumption of ordered food was positively correlated with cardiovascular diseases and higher blood pressure $[8,9]$.

A novel COVID-19 occurred in December 2019 and has developed into a pandemic in March 2020. To curb it, many countries facing the public health crisis have adopted (some are still adopting) relatively strict travel restriction policies $[10,11]$. This has caused more and more catering enterprises to turn to online food ordering operations, as they are unable to operate directly for customers. This trend has also been seen in China. The fact that many families and students are worried about the risk of virus transmission caused by eating close to others has also helped in stimulating the further development of food ordering, although questions about the food safety of ordered food have raised a widespread concern [12]. The long-term impact of COVID-19 on mankind remains unknown, making the duration of social distancing and lockdown measures difficult to foresee $[13,14]$. Some believe that the current social distancing measures may become the new normal of human society in the future
$[15,16]$. Therefore, it is of long-term significance for public health nutrition research to study the new rising food ordering patterns.

A limited number of studies conducted outside China have shown how the youth's food ordering patterns had changed due to the COVID-19 outbreak [17-19]. On the basis of a recent national retrospective survey in China, this study aimed to demonstrate changes in food ordering patterns among the Chinese youth in the months immediately before and after the COVID-19 outbreak. Our timely survey results would inform multiple stakeholders, including policy makers, food (ordering) industry entrepreneurs, health practitioners, and citizens, of the changed food ordering patterns among youths for better policy making and clinical practice during this unusual period, as well as for better preparation for future health emergency events (e.g., more progressive public health intervention, broader health education, and closer public health monitoring).

\section{Materials and Methods}

\section{Study Design, Sample, and Setting}

This study was based on the COVID-19 Impact on Lifestyle Change Survey (COINLICS), a national retrospective survey distributed via social media platforms in early May 2020. More than 10,000 youth participants at 3 educational levels, i.e., high or vocational school (usually aged 15-17), college (usually aged 18-21), and graduate school (usually aged 22-27), in China have voluntarily reported their basic sociodemographic information and food ordering behavior in the month immediately before the COVID-19 outbreak (January 2020, hereafter referred to as before COVID-19) and in the month immediately after the COVID-19 outbreak (February 2020, hereafter referred to as under lockdown) [20-23].

The online questionnaire was designed by a panel consisting of experts in epidemiology, health promotion, and social medicine. Participants were randomly recruited using a snowball sampling method. A web-based questionnaire was initially distributed among several social media groups of educators at all 3 levels, formed during the national conferences in the field. At least 2 educators in each province of China had shared the questionnaire with their surrounding students through chat groups and/or moments on WeChat and Tencent QQ, 2 major social media platforms now trending among Chinese citizens. Those who had completed the questionnaire were also encouraged to forward it to others. An informed consent notice was highlighted on the front page of the questionnaire, and only those who agreed to participate and clicked the "agree" button were allowed to continue the questionnaire. Also, it has been stated on the cover page of the online questionnaire that the youth under 18 cannot proceed with the online survey without both parental consent and their assent. Three commonsensical questions (e.g., what is the capital of China?) were placed among the questions to test the validity of the questionnaire. If any of them were answered incorrectly that questionnaire was considered invalid. The questionnaire was required to be completed online anonymously. 


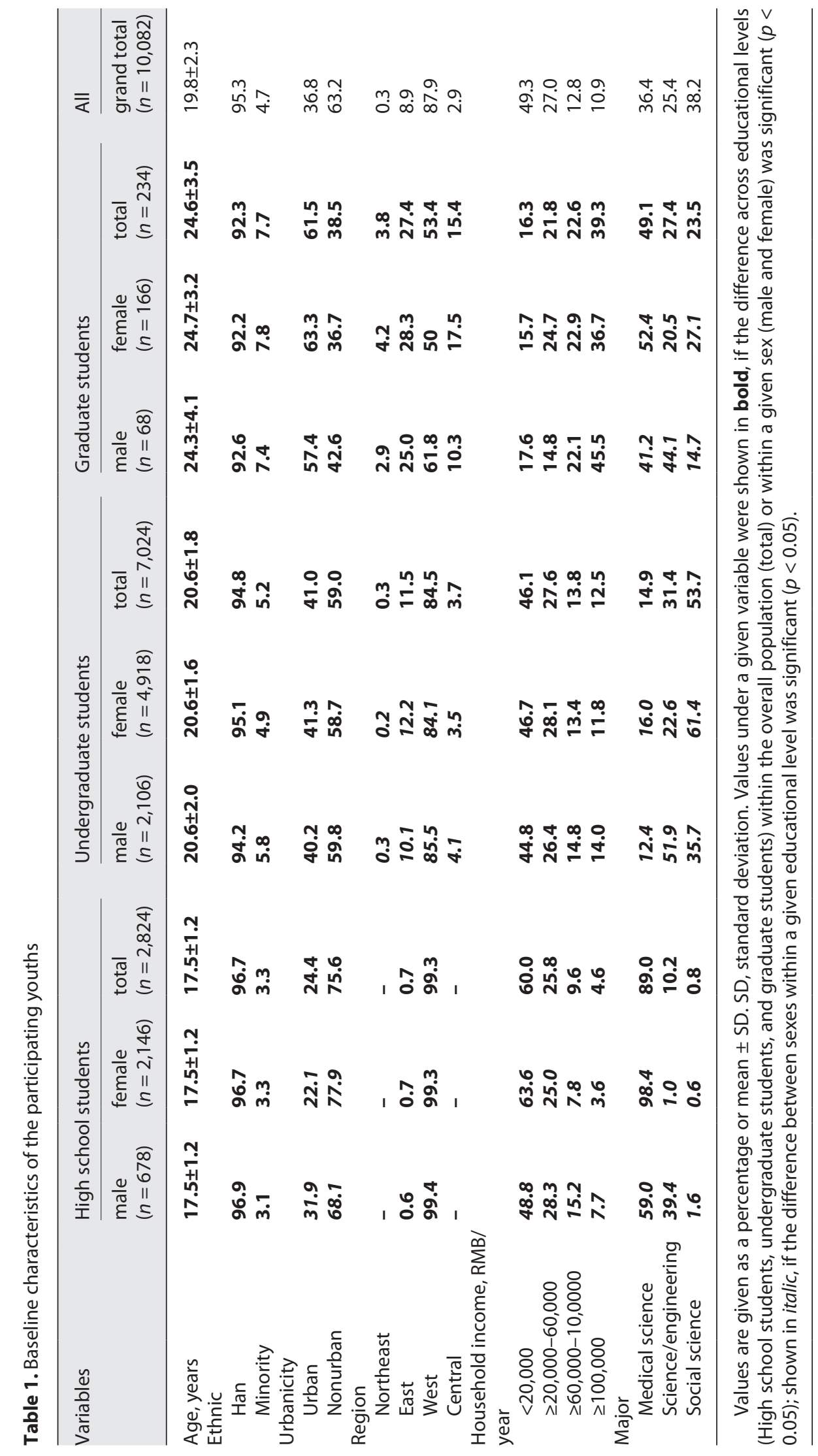




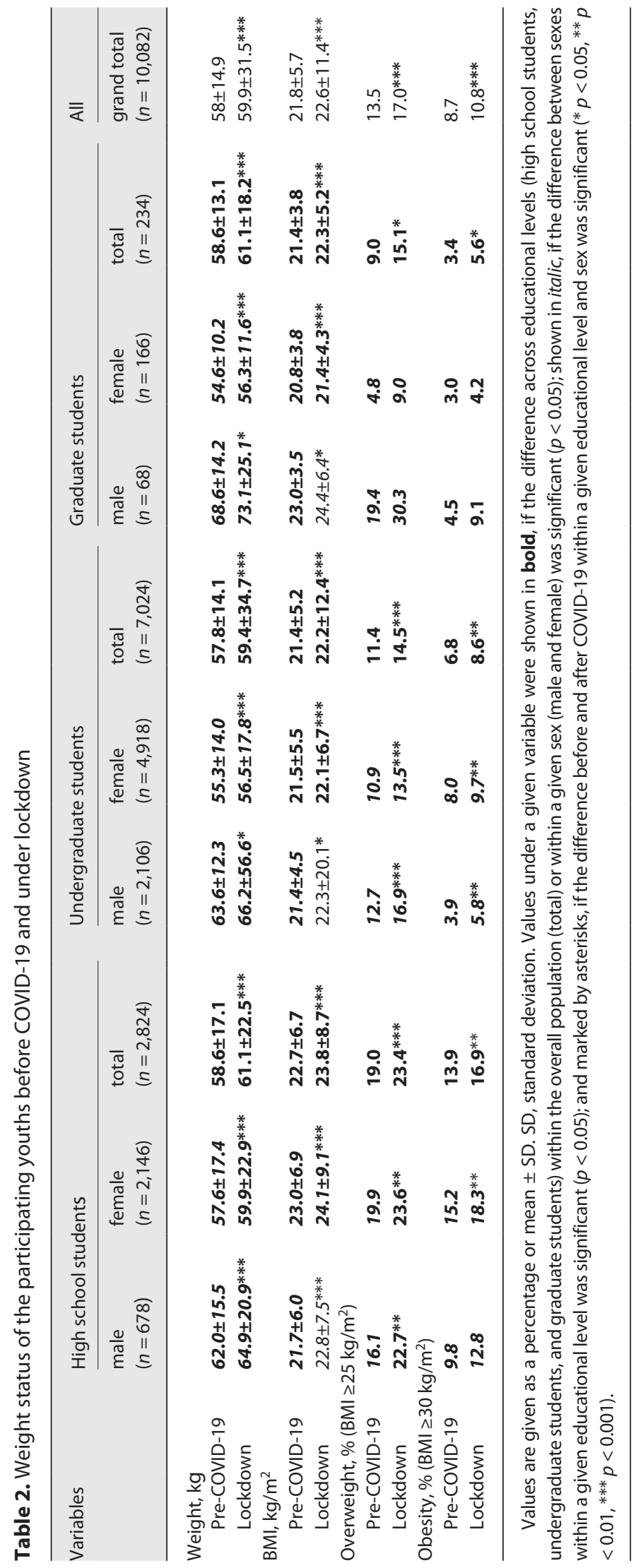

Weight Status Variables

Individuals' height and body weight before COVID-19 and under lockdown were self-recalled. The BMI $\left(\mathrm{kg} / \mathrm{m}^{2}\right)$ for each youth was calculated by dividing body weight by squared height. According to the World Health Organization BMI cutoffs, obesity, and overweight were defined as a BMI of $\geq 25$ or $\geq 30 \mathrm{~kg} / \mathrm{m}^{2}$, respectively, for those aged $>18$; and were defined based on the World Health Organization recommended age-sex-specific cutoffs corresponding to $\mathrm{BMI} \geq 25$ and $\geq 30 \mathrm{~kg} / \mathrm{m}^{2}$ at age 18 , respectively, for those aged $<18[24,25]$.

\section{Measures of Food Ordering Patterns}

Regarding the food ordering patterns, participants self-recalled their average weekly frequency of food ordering for themselves before COVID-19 and under lockdown, by choosing one of the 4 categories of frequency ("daily," " $4-6$ days per week," " $1-3$ days per week," and "none"). The time of food ordering was surveyed by asking participants at which mealtime(s) they often ordered food, which was answered by choosing 1 or more of the 4 mealtimes (breakfast, lunch, dinner, and night snack), common meals in the Chinese culture. Participants were also asked about the main types of food they often ordered, by choosing 1 or more of 10 major categories of the common meals in the Chinese culture: Chinese dish with rice (spicy) hot pot, fried foods or hamburgers, cakes/pastries, simple western meal (e.g., pizza and pasta), barbecue/grill (e.g., Korean barbecue), flour-based food (e.g., noodles, wonton, dumplings, and steamed stuffed buns), braised food, Japanese/Korean food, and others.

\section{Statistical Analyses}

General participants' basic characteristics before and after the COVID-19 outbreak were presented as mean and standard deviation for continuous variables, and as percentage for categorical variables. To enable an intuitive comparison of food ordering patterns in 2 periods, the categories of frequency were converted into continuous variables, i.e., "daily" was denoted by 7 days/week, "4-6 days per week" by 5 days/week, "1-3 days per week" by 2 days/week, and "none" by 0 . The paired $t$ tests (or $\chi^{2}$ tests for categorical variables) were used to evaluate the significance of the differences in weight-related outcomes and the frequency of ordered food and beverage intakes before COVID-19 and under lockdown among all participants, and also in stratified groups by the educational level and sex. $R$ (R Core Team, 2020) was used for all statistical analyses, with $p<0.05$ considered as statistically significant [12].

\section{Results}

In total, 10,082 young people from a wide range of regions in China, covering all provinces, participated in the survey and completed a valid questionnaire. Among them, $71.7 \%$ were female, $4.7 \%$ were adolescent, and $63.2 \%$ were from nonurban areas. No significant difference in the age and ethnic distribution has been found between males and females. Most high/vocational school and graduate participants were majoring in medical sci- 
ence, while the majority of undergraduate participants were majoring in social science (Table 1).

During the month after the outbreak, all subgroups had seen a statistically significant increase in body weight, with an average increase of $1.9 \mathrm{~kg}(p<0.001)$ (Table 2). Prior to COVID-19, the mean BMI of all youths was 21.8 $\mathrm{kg} / \mathrm{m}^{2}$, with the prevalence of overweight and obesity being 13.5 and $8.7 \%$, respectively. The mean BMI was similar between sexes in undergraduates $\left(21.4 \mathrm{~kg} / \mathrm{m}^{2}\right)$, higher in female than in male high school students $(23.0 \%$ vs. $21.7 \%, p<0.05)$, and higher in male than in female graduate students ( $23.0 \%$ vs. $20.8 \%, p<0.05)$. During the lockdown period, BMI had significantly increased in overall youths $\left(21.8-22.6 \mathrm{~kg} / \mathrm{m}^{2}, p<0.001\right)$ and in all subgroups: high school $\left(22.7-23.8 \mathrm{~kg} / \mathrm{m}^{2}, p<0.001\right)$, undergraduate $\left(21.4-22.2 \mathrm{~kg} / \mathrm{m}^{2}, p<0.001\right)$, and graduate students $\left(21.4-22.3 \mathrm{~kg} / \mathrm{m}^{2}, p<0.001\right)$. About $30 \%$ of the young people reported a weight gain, while about $10 \%$ reported a weight loss, and $60 \%$ reported no apparent change. Moreover, the prevalence of overweight/obesity had significantly increased overall $(13.5-17.0 \%, p<0.001)$ and in all 3 educational groups: high school (19.0-23.4\%, $p<$ $0.001)$, undergraduate $(11.4-14.5 \%, p<0.001)$, and graduate students $(9.0-15.1 \%, p<0.05)$; obesity prevalence had also significantly increased overall $(8.7-10.8 \%, p<$ $0.001)$ and among high school $(13.9-16.9 \%, p<0.01)$, undergraduate $(6.8-8.6 \%, p<0.01)$, and graduate students $(3.4-5.6 \%, p<0.05)$.

The food ordering patterns had changed significantly after the COVID-19 outbreak (Table 3). The average weekly frequency of ordering food decreased from 0.4 to 0.1 times/week $(p<0.001)$, with the largest decrease seen among graduate students $(1.0-0.1, p<0.001)$, followed by undergraduate $(0.5-0.2, p<0.001)$ and high school students $(0.2-0.1, p<0.001)$. These decreases were mainly accounted for by significantly increased percentages of those who did not order food (84.6-95.6\%, $p<0.001)$, which also varied among graduate (66.7-95.7\%, $p<$ $0.001)$, undergraduate $(81.7-95.0 \%, p<0.001)$ and high school students $(93.1-97.0 \%, p<0.001)$. According to individual-level changes in food ordering patterns, we observed that a larger percentage (92.1\%) of high school students had never ordered food before COVID-19 and under lockdown, compared to undergraduate $(80.6 \%)$ and graduate students $(65.4 \%)$. Hence, larger percentages of graduate $(30.3 \%)$ and undergraduate students $(14.4 \%)$ stopped ordering food during the lockdown period than high school students (4.9\%); despite a smaller percentage of undergraduate than graduate students, most who had stopped ordering food under lockdown were undergrad- uate students due to their larger sample size. Most of participating youths had never ordered food for breakfast $(98.3 \%)$ or midnight snacks (95.8\%) before COVID-19. Also, large percentages of the participating youths had never ordered food for dinner (91.2\%) or lunch (88.6\%), most of which were undergraduate students, although the percentage was larger for graduate students relative to the total sample size of that group. However, regardless of types of food, the percentage of youths who started ordering was much lower than that of youths who stopped ordering under lockdown. In addition, the decline in the frequency of food ordering was seen regardless of weight change status during the lockdown, with the most apparent decline observed among the graduate students with increased weight (Table 4). Compared to the groups with constant and increased weight during the lockdown, those with decreased weight had a larger proportion stopping ordering fried foods or hamburgers ( $p<0.05$ for undergraduate students) and simple western meals ( $p<0.05$ for undergraduate students).

Among those who had been ordering food before COVID-19 and under lockdown, percentages of ordering (spicy) hot pot and cakes/pastries before COVID-19 were higher in female than male high school and undergraduate students; also, a larger percentage of female than male high school students ordered fried foods or hamburgers, and a larger percentage of male than female undergraduate students ordered the Chinese dishes (Table 5). In addition, differences in ordering the Chinese dishes (spicy) hot pot, fried foods or hamburgers, barbecue/grill, braised foods, and Japanese/Korean foods were significant across the 3 educational groups, with the highest percentages of ordering braised foods observed in undergraduate students (15.1\%) and of ordering the Chinese dishes in graduate students (67.9\%), the lowest percentages of ordering fried foods or hamburgers (29.5\%) and barbecue/grill $(14.1 \%)$ in graduate students, and the lowest percentages of ordering (spicy) hot pot (48.5\%) and Japanese/Korean foods $(6.2 \%)$ in high school students. The percentages of ordering most types of food did not vary across the groups of weight change status at any educational level, except the percentages of ordering fried foods or hamburgers and barbecue/grill among graduate students (Table 6). During the lockdown period, only female high school students were found to have a larger percentage of ordering barbecue/grill (34.0\% vs. 9.7\%) and cakes/pastries (54.7\% vs. $22.6 \%)$ relative to their male counterparts. No significant differences were found across the educational levels (Table 5). 
Table 3. Food ordering patterns of the participating youths before COVID-19 and under lockdown, by educational level and sex

\begin{tabular}{|c|c|c|c|c|c|c|c|c|c|c|}
\hline \multirow[t]{2}{*}{ Variables } & \multicolumn{3}{|c|}{ High school students } & \multicolumn{3}{|c|}{ Undergraduate students } & \multicolumn{3}{|c|}{ Graduate students } & \multirow{2}{*}{$\begin{array}{l}\text { All } \\
\text { grand total } \\
(n=10,082)\end{array}$} \\
\hline & $\begin{array}{l}\text { male } \\
(n=678)\end{array}$ & $\begin{array}{l}\text { female } \\
(n=2,146)\end{array}$ & $\begin{array}{l}\text { total } \\
(n=2,824)\end{array}$ & $\begin{array}{l}\text { male } \\
(n=2,106)\end{array}$ & $\begin{array}{l}\text { female } \\
(n=4,918)\end{array}$ & $\begin{array}{l}\text { total } \\
(n=7,024)\end{array}$ & $\begin{array}{l}\text { male } \\
(n=68)\end{array}$ & $\begin{array}{l}\text { female } \\
(n=166)\end{array}$ & $\begin{array}{l}\text { total } \\
(n=234)\end{array}$ & \\
\hline
\end{tabular}

Weekly frequency of food ordering

Pre-COVID-19

\begin{tabular}{|c|c|c|c|c|c|c|c|c|c|c|}
\hline None & 92.0 & 93.5 & 93.1 & 83.8 & 80.9 & 81.7 & 77.9 & 62.0 & 66.7 & 84.6 \\
\hline 1-3 days/week & 6.5 & 5.5 & 5.8 & 11.2 & 16.0 & 14.6 & 19.1 & 26.5 & 24.4 & 12.3 \\
\hline 4-6 days/week & 0.6 & 0.5 & 0.5 & 2.6 & 1.8 & 2.0 & 3.0 & 4.3 & 3.8 & 1.6 \\
\hline 7 days/week & 0.9 & 0.5 & 0.6 & 2.4 & 1.3 & 1.7 & 0.0 & 7.2 & 5.1 & 1.5 \\
\hline \multicolumn{11}{|c|}{ ockdown, days/week } \\
\hline None & $95.4^{* * *}$ & $97.5^{* * *}$ & $97.0 * * *$ & $93.4^{* * *}$ & $95.6 * * *$ & $95.0 * * *$ & $92.6^{* * *}$ & $97.0 * * *$ & $95.7^{* * *}$ & $95.6^{* * *}$ \\
\hline $1-3$ & $3.2^{* * *}$ & $1.9 * * *$ & $2.2 * * *$ & $4.4^{* * * *}$ & $3.2 * * *$ & $3.6^{* * * *}$ & $4.4^{* * *}$ & $3.0 * * *$ & $3.4^{* * *}$ & $3.2^{* * *}$ \\
\hline $4-6$ & $0.9^{* * *}$ & $0.3^{* * *}$ & $0.4^{* * *}$ & $1.1^{* * *}$ & $0.8^{* * *}$ & $0.8^{* * *}$ & $0.0^{* * *}$ & $0.0 * * *$ & $0.0 * * *$ & $0.7^{* * *}$ \\
\hline 7 & $0.5^{* * *}$ & $0.3^{* * *}$ & $0.4^{* * *}$ & $1.1^{* * *}$ & $0.4^{* * *}$ & $0.6 * * *$ & $3.0 * * *$ & $0.0^{* * *}$ & $0.9^{* * *}$ & $0.5^{* * *}$ \\
\hline
\end{tabular}

Average weekly frequency of food ordering, days/week

Pre-COVID-19
Lockdown

dividual-level changes in food ordering

\begin{tabular}{|c|c|c|c|c|c|c|c|c|c|c|}
\hline Started ordering & 1.3 & 0.9 & 1.0 & 0.9 & 1.3 & 1.2 & 1.5 & 1.2 & 1.3 & 1.1 \\
\hline Stopped ordering & 4.7 & 4.9 & 4.9 & 10.5 & 16.1 & 14.4 & 16.2 & 36.1 & 30.3 & 12.1 \\
\hline Increased & 0.3 & 0.2 & 0.2 & 0.5 & 0.4 & 0.4 & 2.9 & 0.0 & 0.9 & 0.4 \\
\hline Decreased & 0.6 & 0.2 & 0.3 & 1.0 & 0.4 & 0.6 & 0.0 & 0.7 & 0.4 & 0.5 \\
\hline Constant & 2.4 & 1.2 & 1.5 & 4.1 & 2.3 & 2.8 & 2.9 & 1.2 & 1.7 & 2.4 \\
\hline Never & 90.7 & 92.6 & 92.1 & 83.0 & 79.5 & 80.6 & 76.5 & 60.8 & 65.4 & 83.5 \\
\hline
\end{tabular}

Individual-level changes by ordering time

\section{Breakfast}

\begin{tabular}{|c|c|c|c|c|c|c|c|c|c|c|}
\hline \\
\hline Started ordering & 1.0 & 0.3 & 0.5 & 0.4 & 0.3 & 0.3 & 0.0 & 0.0 & 0.0 & 0.4 \\
\hline Stopped ordering & 0.9 & 0.6 & 0.6 & 1.4 & 1.1 & 1.2 & 0.0 & 0.6 & 0.5 & 1.0 \\
\hline Constant & 0.3 & 0.4 & 0.4 & 0.5 & 0.2 & 0.3 & 0.0 & 0.6 & 0.4 & 0.3 \\
\hline Never & 97.8 & 98.7 & 98.5 & 97.7 & 98.4 & 98.2 & 100.0 & 98.8 & 99.1 & 98.3 \\
\hline \multicolumn{11}{|l|}{ Lunch } \\
\hline Started ordering & 0.1 & 0.7 & 0.7 & 1.4 & 0.9 & 1.0 & 1.5 & 0.6 & 0.9 & 0.9 \\
\hline Stopped ordering & 3.7 & 2.2 & 2.5 & 8.3 & 12.2 & 11.0 & 10.3 & 28.9 & 23.5 & 8.9 \\
\hline Constant & 0.9 & 0.8 & 0.8 & 2.4 & 1.6 & 1.9 & 4.4 & 1.8 & 2.6 & 1.6 \\
\hline Never & 95.3 & 96.3 & 96.0 & 87.9 & 85.3 & 86.1 & 83.8 & 68.7 & 73.0 & 88.6 \\
\hline \multicolumn{11}{|l|}{ Dinner } \\
\hline Started ordering & 0.9 & 0.4 & 0.5 & 1.1 & 0.9 & 1.0 & 1.5 & 1.2 & 1.3 & 0.9 \\
\hline Stopped ordering & 1.3 & 2.1 & 1.9 & 6.7 & 8.7 & 8.1 & 10.3 & 22.3 & 18.8 & 6.6 \\
\hline Constant & 0.9 & 0.6 & 0.7 & 2.0 & 1.4 & 1.6 & 2.9 & 1.2 & 1.7 & 1.3 \\
\hline Never & 96.9 & 96.9 & 96.9 & 90.2 & 89.0 & 89.3 & 85.3 & 75.3 & 78.2 & 91.2 \\
\hline \multicolumn{11}{|l|}{ Midnight snack } \\
\hline Started ordering & 1.2 & 0.4 & 0.6 & 0.6 & 0.6 & 0.6 & 0.0 & 0.0 & 0.0 & 0.6 \\
\hline Stopped ordering & 1.3 & 2.1 & 1.9 & 3.3 & 3.1 & 3.1 & 1.5 & 2.4 & 2.1 & 2.8 \\
\hline Constant & 0.9 & 0.5 & 0.6 & 1.6 & 0.7 & 1.0 & 0.0 & 0.0 & 0.0 & 0.8 \\
\hline Never & 96.6 & 97.0 & 96.9 & 94.5 & 95.6 & 95.3 & 98.5 & 97.6 & 97.9 & 95.8 \\
\hline \multicolumn{11}{|c|}{$\begin{array}{l}\text { Individual-level changes by type of food ordered } \\
\text { Chinese dishes with rice }\end{array}$} \\
\hline Started ordering & 0.7 & 0.5 & 0.5 & 1.0 & 0.9 & 0.8 & 0.0 & 0.6 & 0.4 & 0.7 \\
\hline Stopped ordering & 2.9 & 1.7 & 2.0 & 7.0 & 7.5 & 7.4 & 14.7 & 24.1 & 21.4 & 6.2 \\
\hline Constant & 0.7 & 0.4 & 0.5 & 1.4 & 0.9 & 1.1 & 4.4 & 0.0 & 1.3 & 0.9 \\
\hline Never & 95.7 & 97.4 & 97.0 & 90.6 & 90.7 & 90.7 & 80.9 & 75.3 & 76.9 & 92.2 \\
\hline \multicolumn{11}{|l|}{ (Spicy) hot pot } \\
\hline Started ordering & 0.8 & 0.6 & 0.7 & 1.0 & 1.1 & 1.1 & 0.0 & 1.2 & 0.9 & 1.0 \\
\hline Stopped ordering & 1.6 & 2.9 & 2.6 & 5.4 & 11.0 & 9.3 & 7.4 & 23.5 & 18.8 & 7.6 \\
\hline Constant & 0.7 & 0.7 & 0.7 & 2.0 & 1.3 & 1.5 & 1.5 & 1.2 & 1.3 & 1.3 \\
\hline Never & 96.9 & 95.8 & 96.0 & 91.6 & 86.6 & 88.1 & 91.1 & 74.1 & 79.0 & 90.1 \\
\hline
\end{tabular}

$\begin{array}{lllllll}0.5 \pm 1.4 & 0.5 \pm 1.2 & 0.5 \pm 1.3 & 0.5 \pm 1.1 & 1.2 \pm 2.0 & 1.0 \pm 1.8 & 0.4 \pm 1.2\end{array}$

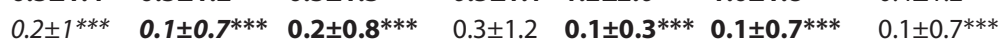


Table 3 (continued)

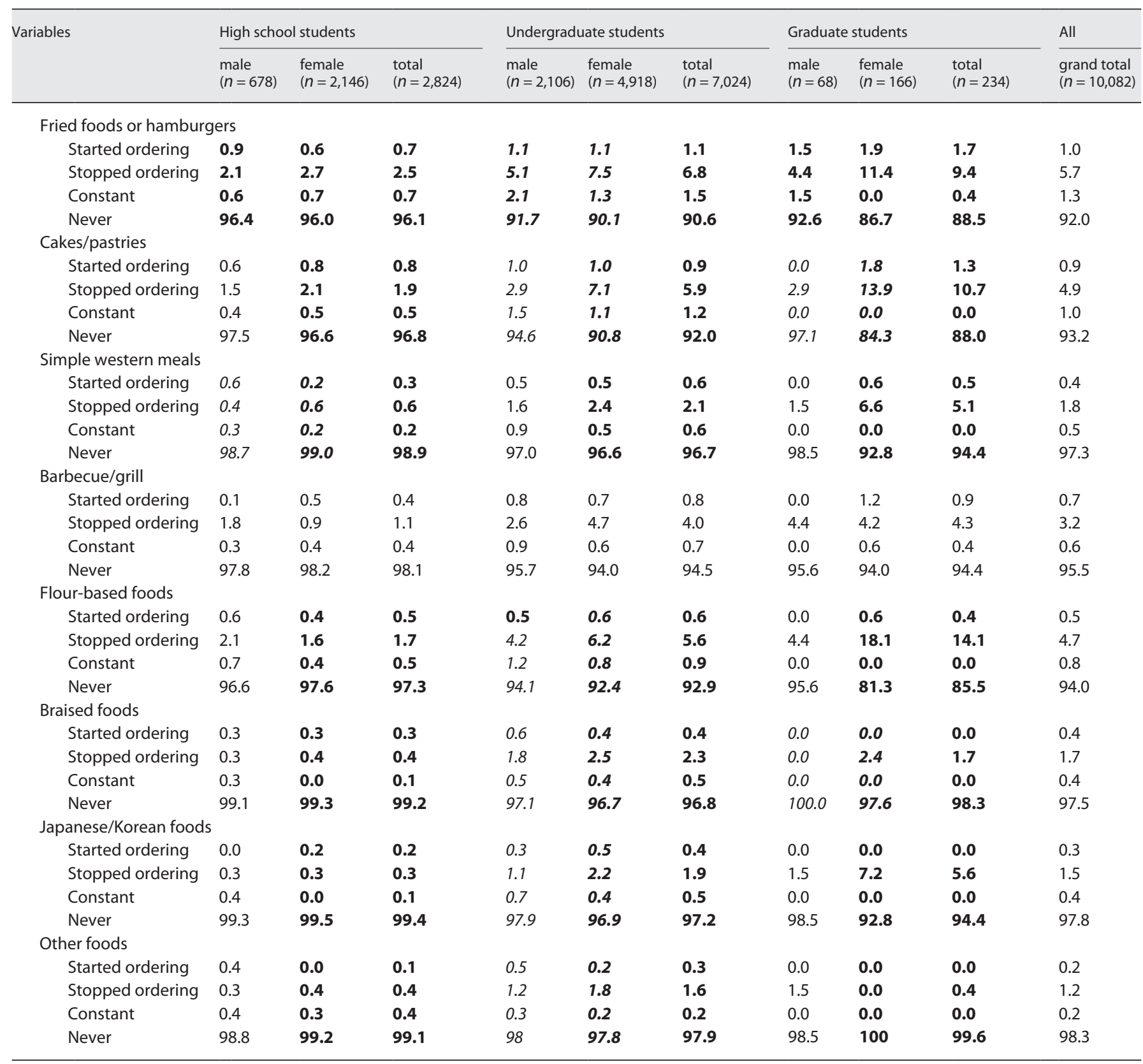

Values are given as a percentage or mean \pm SD. SD, standard deviation. Values under a given variable were shown in bold, if the difference across educational levels (high school students, undergraduate students, and graduate students) within the overall population (total) or within a given sex (male and female) was significant $(p<0.05)$; shown in italic, if the difference between sexes within a given educational level was significant $(p<0.05)$; and marked by asterisks, if the difference before and after COVID-19 within a given educational level and sex was significant $\left({ }^{*} p<0.05,{ }^{* *} p<0.01,{ }^{* * *} p<0.001\right)$.

Lockdown Impact on Food Ordering Patterns in China
Obes Facts 2022;15:135-149

DOI: $10.1159 / 000520160$ 


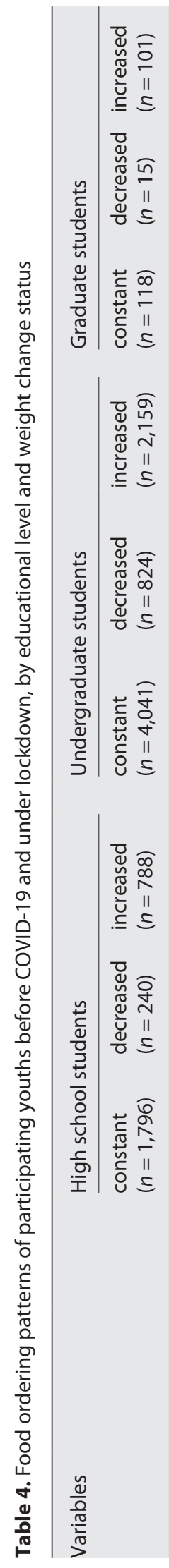

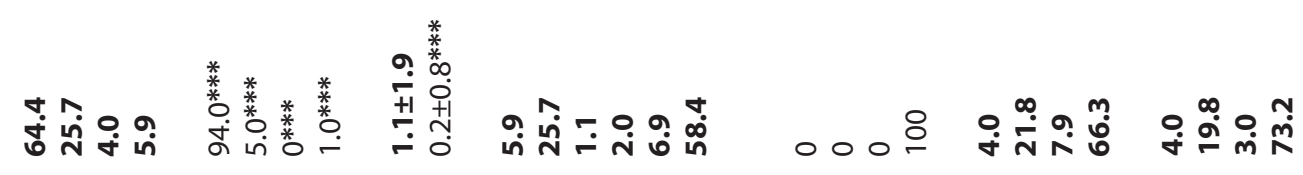

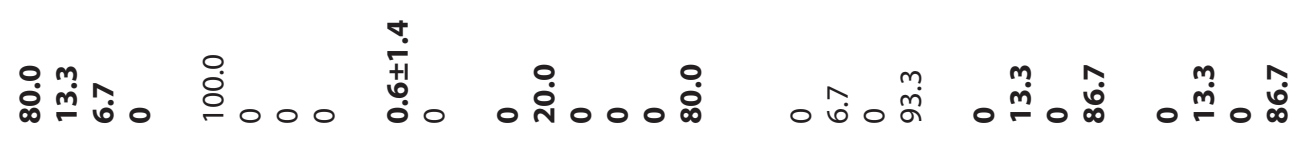

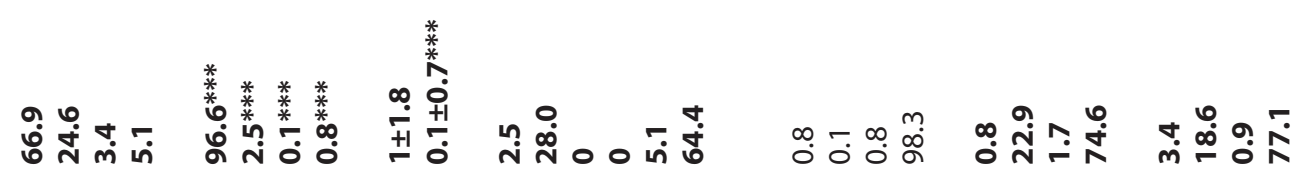

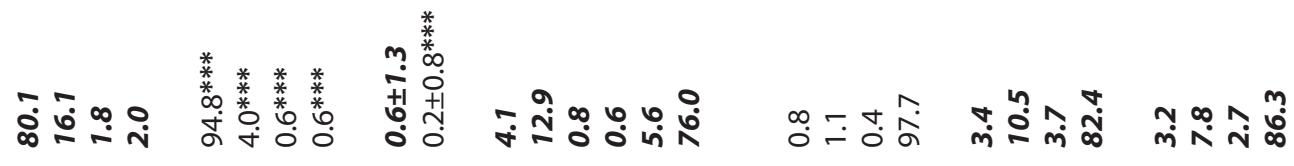

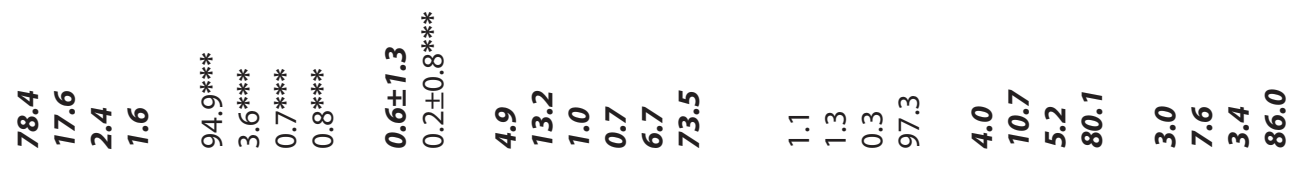

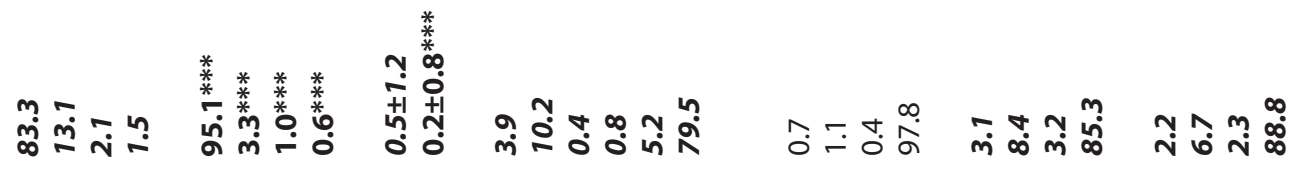

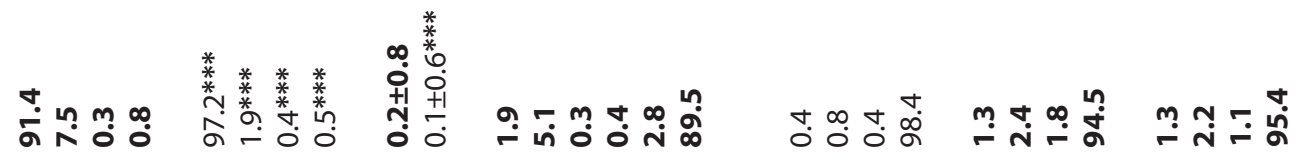

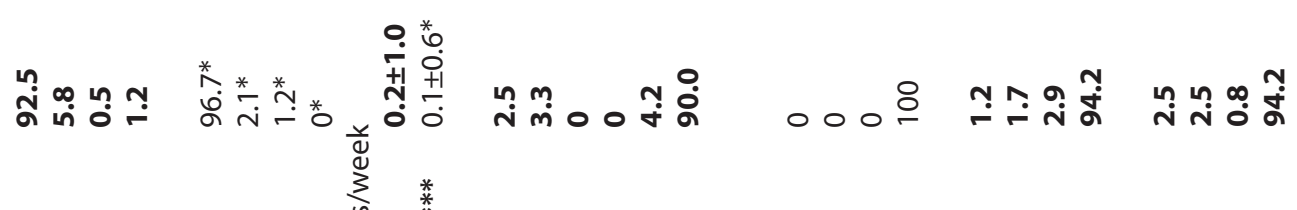

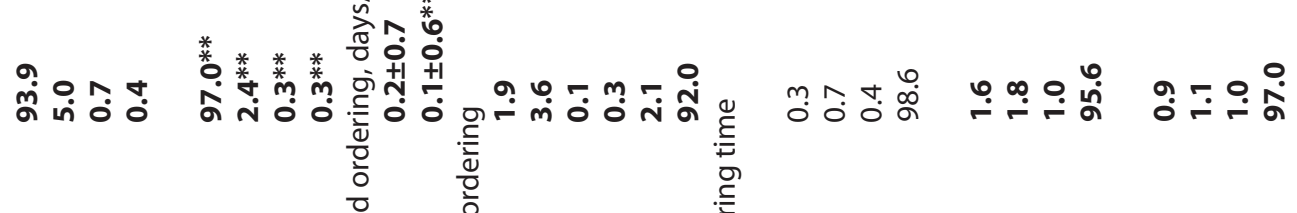

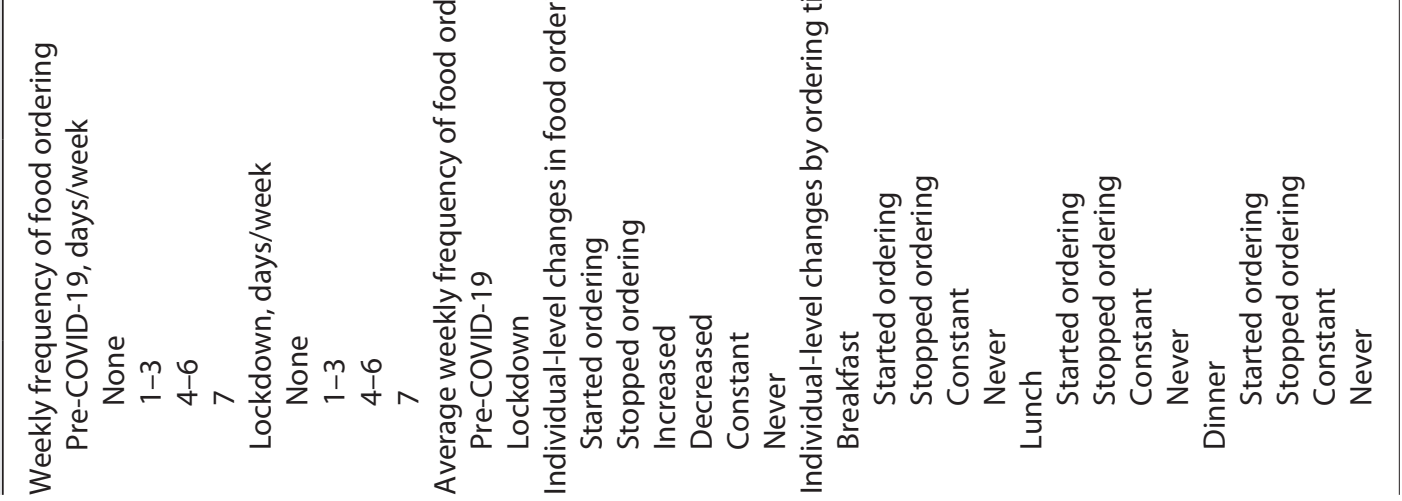




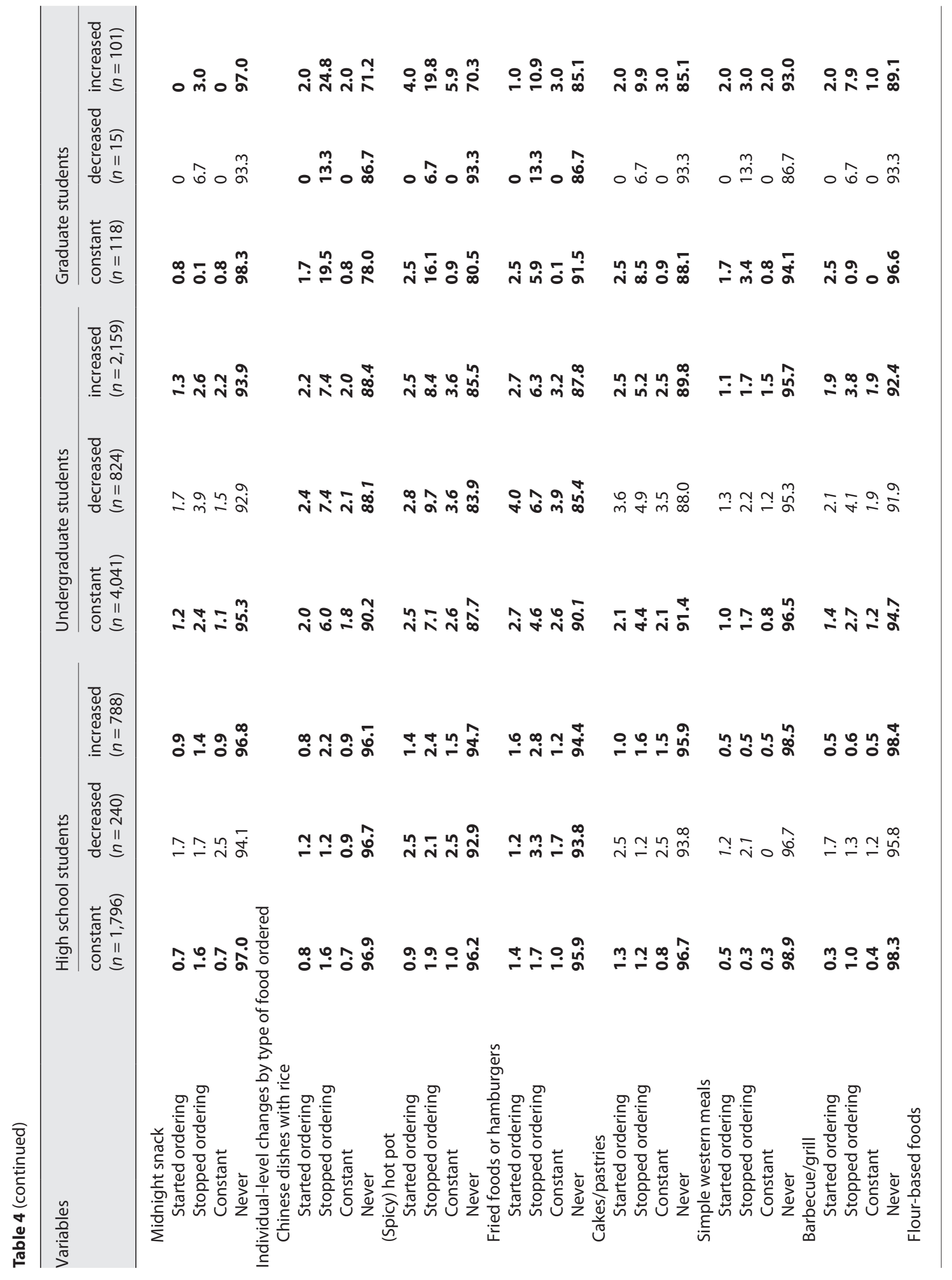




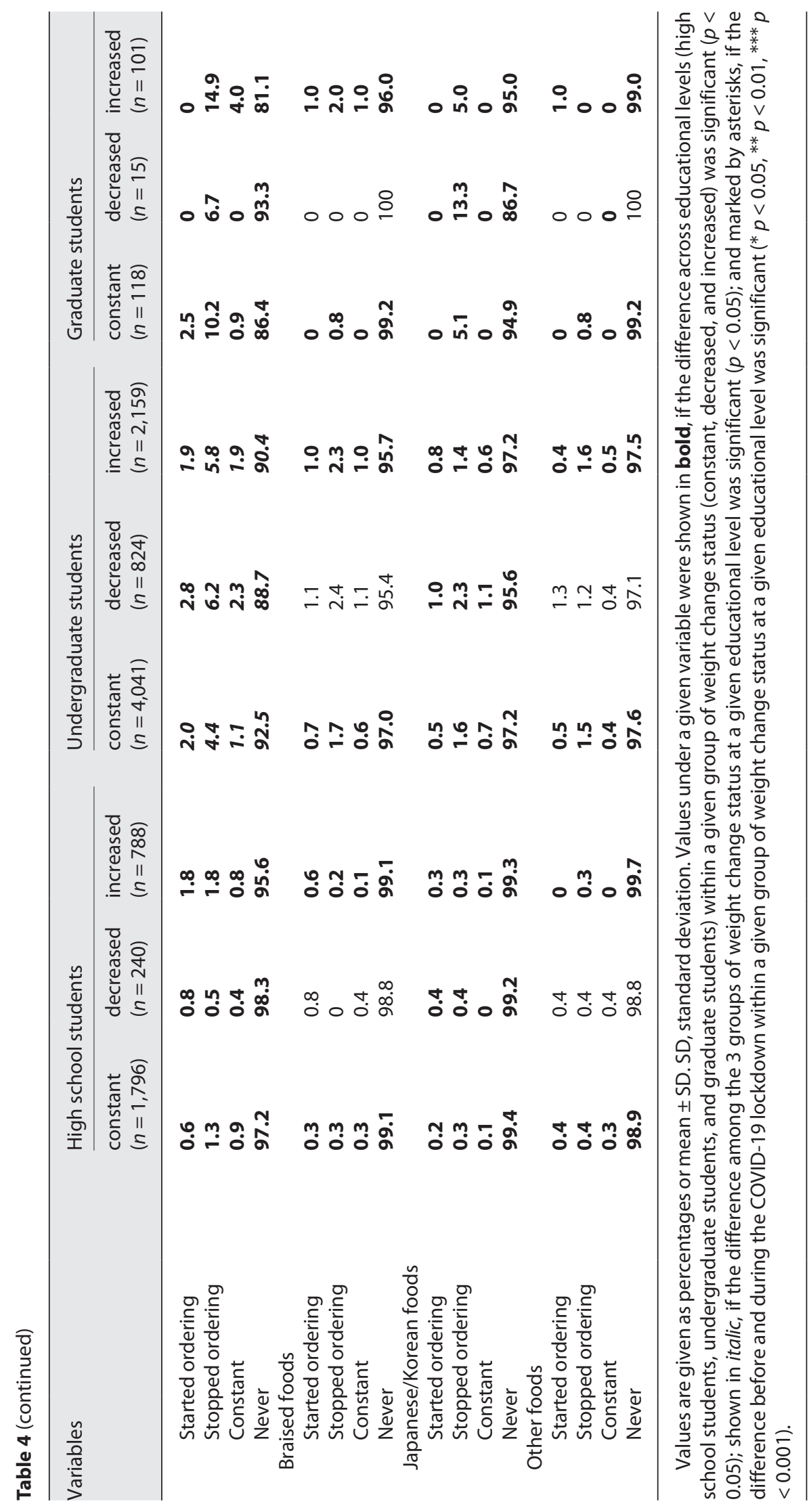


Table 5. Changes in food ordering patterns of the participating youths who have ordered food before COVID-19 and under lockdown, by educational level and sex

\begin{tabular}{|c|c|c|c|c|c|c|c|c|c|c|}
\hline \multirow[t]{2}{*}{ Variables } & \multicolumn{3}{|c|}{ High school students } & \multicolumn{3}{|c|}{ Undergraduate students } & \multicolumn{3}{|c|}{ Graduate students } & \multirow{2}{*}{$\begin{array}{l}\text { All } \\
\text { grand total } \\
(n=1,552)\end{array}$} \\
\hline & $\begin{array}{l}\text { male } \\
(n=54)\end{array}$ & $\begin{array}{l}\text { female } \\
(n=140)\end{array}$ & $\begin{array}{l}\text { total } \\
(n=194)\end{array}$ & $\begin{array}{l}\text { male } \\
(n=341)\end{array}$ & $\begin{array}{l}\text { female } \\
(n=939)\end{array}$ & $\begin{array}{l}\text { total } \\
(n=1,280)\end{array}$ & $\begin{array}{l}\text { male } \\
(n=15)\end{array}$ & $\begin{array}{l}\text { female } \\
(n=63)\end{array}$ & $\begin{array}{l}\text { total } \\
(n=78)\end{array}$ & \\
\hline
\end{tabular}

\section{Pre-COVID-19}

Ordering time Breakfast

Lunch

Dinner

14.8

57.4

14.3

$\mathbf{1 4 . 4} \quad 11.5$

45.7

49.0

\section{7}

6.8

37.1

54.3

Midnight snack

27.8
27.8

40.7
38.6

35.6

30.1

Type of food ordered

Chinese dishes with rice

(Spicy) hot pot

46.3

29.6

Fried foods or hamburgers 33.3

Cakes/pastries $\quad 24.1$

Simple western meals $\quad 9.3$

Barbecue/Grill 25.9

Flour-based foods

Braised foods

35.2

7.4

Japanese/Korean foods

9.3

Other foods

\section{1}

55.7

$\mathbf{5 2 . 1}$

40.0

12.9

19.3

30.7

6.4

36.1

48.5

46.9

35.6

11.9

21.1

32.0

6.7

5.0

6.7

$\begin{array}{ll}7.1 & 7.7\end{array}$

$\begin{array}{ll}6.8 & 8.0 \\ 72.3 & 70.8 \\ 52.7 & 53.1 \\ 19.9 & 22.6\end{array}$

0

3.2

2.6

66.7

$\mathbf{6 0 . 0}$

81.0

78.2

$19.9 \quad 22.6$

6.7

6.3

$61.5 \quad 51.5$

\section{5}

45.7

$44.3 \quad 46.5$

$64.4 \quad \mathbf{5 9 . 5}$

$\begin{array}{lll}44.5 & 46.0 & 45.6\end{array}$

$\begin{array}{lll}27.1 & 43.3 & 39.0\end{array}$

$\begin{array}{lll}15.3 & 15.3 & 15.3\end{array}$

$\begin{array}{lll}21.8 & \mathbf{2 7 . 3} & \mathbf{2 5 . 9}\end{array}$

$\begin{array}{lll}33.9 & 36.5 & 35.8\end{array}$

$\begin{array}{lll}14.2 & \mathbf{1 5 . 4} & \mathbf{1 5 . 1}\end{array}$

$\begin{array}{lll}11.2 & \mathbf{1 3 . 4} & \mathbf{1 2 . 8}\end{array}$

$\begin{array}{llllllllll}\text { male } & \text { female } & \text { total } & \text { male } & \text { female } & \text { total } & \text { male } & \text { female } & \text { total } & \text { grand total } \\ (n=31) & (n=54) & (n=85) & (n=139) & (n=216) & (n=355) & (n=5) & (n=5) & (n=10) & (n=450)\end{array}$

Lockdown

Ordering time

Breakfast

Lunch

29.0
$\mathbf{2 2 . 6}$
38.7
45.2

29.0
32.3
32.3
22.6
19.4
9.7
29.0
12.9
9.7
19.4

$\mathbf{2 8 . 3}$
62.3
41.5
35.8

35.8
54.7
54.7
54.7
17.0
34.0
32.1
15.1
9.4
15.1

$\mathbf{2 8 . 6}$
47.6
40.5
39.3

33.3
46.4
46.4
42.9
17.9
25.0
31.0
14.3
9.5
16.7

$\begin{array}{ll}13.8 & \mathbf{1 1 . 2} \\ \mathbf{5 8 . 0} & 57.0 \\ 47.1 & 52.3 \\ 32.6 & 30.4 \\ & \\ 35.5 & 39.3 \\ 45.7 & 54.7 \\ 48.6 & 53.3 \\ 37.7 & 46.7 \\ 21.0 & 23.4 \\ 26.8 & 29.4 \\ 26.1 & 30.8 \\ 17.4 & 17.8 \\ 15.2 & 20.1 \\ 12.3 & 8.9\end{array}$

$\mathbf{1 2 . 2}$
57.4
50.3
$\mathbf{3 1 . 2}$

37.8
51.1
51.4
43.2
22.4
28.4
29.0
17.6
18.2
10.2

0
80.0
60.0
0

60.0
20.0
40.0
0
0
0
0
0
0
0

20.0
80.0
80.0
0

20.0
80.0
60.0
60.0
20.0
60.0
20.0
0
0
0

$\begin{array}{ll}\mathbf{1 0 . 0} & 15.2 \\ 80.0 & 56.1 \\ 70.0 & 48.9 \\ \mathbf{0} & 32.1 \\ & \\ 40.0 & 37.0 \\ 50.0 & 50.2 \\ 50.0 & 50.4 \\ 30.0 & 42.8 \\ 10.0 & 21.3 \\ 30.0 & 27.8 \\ 10.0 & 28.9 \\ 0 & 16.6 \\ 0 & 16.1 \\ 0 & 11.2\end{array}$

Values are given as percentages or mean \pm SD. SD, standard deviation. Values under a given variable were shown in bold, if the difference across educational levels (high school students, undergraduate students, and graduate students) within the overall population (total) or within a given sex (male and female) was significant $(p<0.05)$; and shown in italic, if the difference between sexes within a given educational level was significant $(p<0.05)$.

\section{Discussion/Conclusion}

In this nationwide survey among youths in China, we found an increased level of average BMI and of the prevalence of overweight and obesity among the participants after the COVID-19 outbreak, specifically among high school and undergraduate students. Also, we observed significant changes in food ordering patterns after the COVID-19 outbreak. Overall, the average weekly frequency of food ordering among the Chinese students had declined, with the largest decrease seen among graduate students (due to the highest percentage of food ordering 
Table 6. Changes in food ordering patterns of the participating youths who have ordered food before COVID-19 and under lockdown, by educational level and weight change status

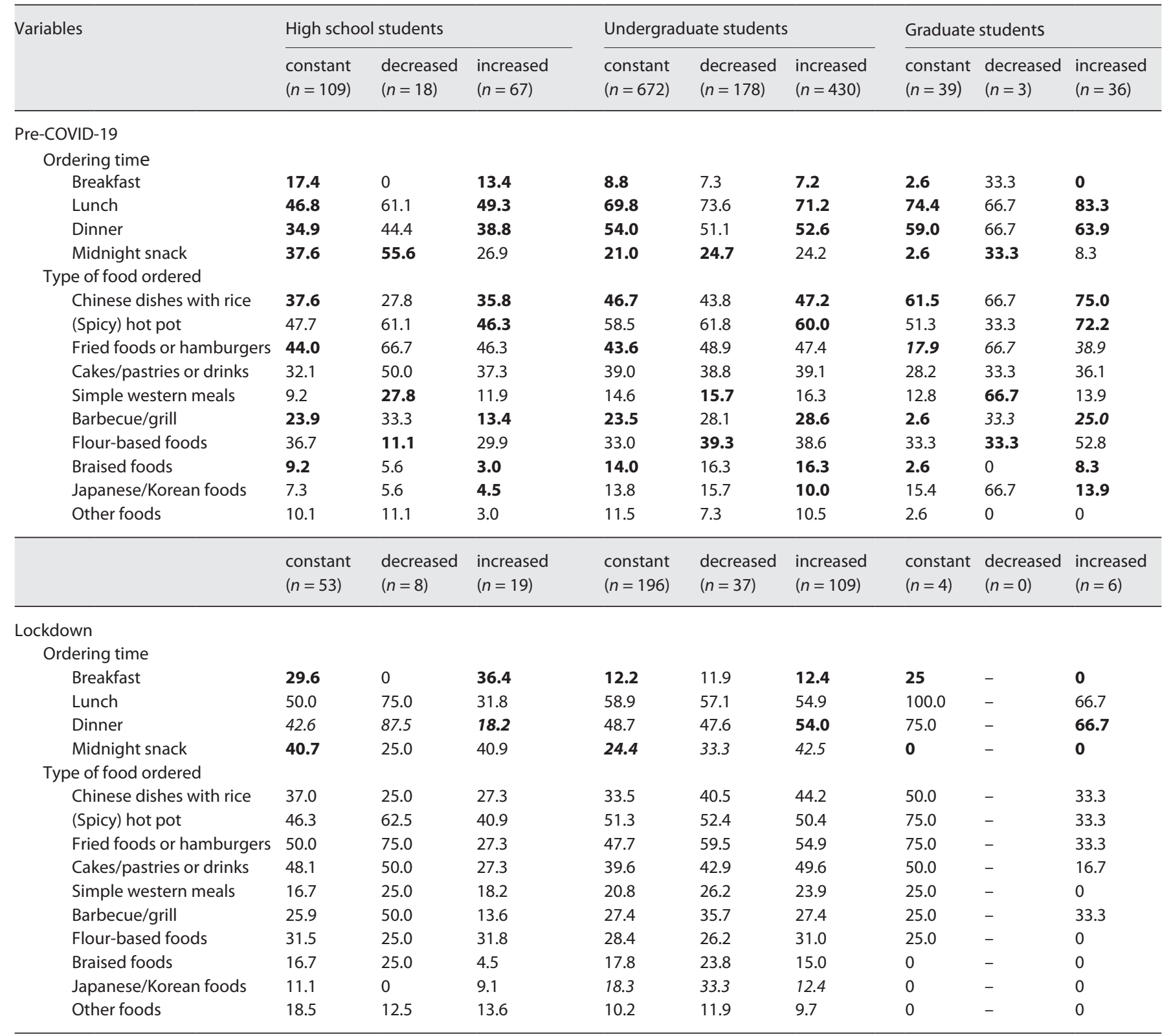

Values are give as percentage or mean \pm SD. SD, standard deviation. Values under a given variable were shown in bold, if the difference across educational levels (high school students, undergraduate students, and graduate students) within a given group of weight change status (constant, decreased, and increased) was significant $(p<0.05)$; and shown in italic, if the difference among the 3 groups of weight change status at a given educational level was significant $(p<0.05)$.

food in this group before COVID-19), followed by undergraduate and high school students. Also, regardless of types of food, the percentage of participating youths who started ordering was all lower than that of youths who stopped ordering under lockdown.
The observed decreases in the frequency of ordering food among the Chinese students after the COVID-19 outbreak is contrary to previous reports about the rise of the food ordering industry [5]. Concerns about the risk of infection via contact with food deliverers could make 
people less inclined to order food. Another important reason may be that, at the time of the outbreak of COVID-19, the Chinese were preparing to celebrate the Spring Festival, before which foods are generally sufficiently stored [26, 27]. Moreover, most students return home to spend most of their time with families during Spring Festival, which, together with traffic control during the outbreak, may make them prefer to cook at home with their families in their leisure time rather than ordering food. Changes in youth's food ordering patterns may also reflect changes in the operation of China's catering industry during the lockdown. On the one hand, due to traffic control and travel restrictions, a large percentage of China's catering operators had suspended their business including their takeout business; on the other hand, in large cities, people may need to order foods due to concerns about the risk while going out. These contradictory changes in demand and supply for food ordering may imply that governments and relevant companies and organizations need to work together on more active measures for coordinating market provision and competition during public health emergencies.

Although the frequency of ordering food among youths had decreased, percentages of ordering non-Chinese foods (i.e., fried foods or hamburgers, cakes/pastries, simple western meals, barbecue/grill, and Japanese/Korean foods) and ordering breakfast and midnight snacks had increased among those who had ordered foods before COVID-19 and under lockdown. Many types of the nonChinese foods ordered are high in sugar and fat and could lead to increased weight gain [28], which was also observed in our study. However, there might be other reasons of the increased prevalence of obesity. For example, with the accumulation of unstructured time, people are more vulnerable to overeating and sedentary behaviors. Also, due to the epidemic, stress and depression may also trigger the increased weight status through excessive consumption of sweets, for example [29]. Therefore, future studies are warranted to investigate potential pathways underlying the observed changes (i.e., from lockdown to weight gain), which would enable evidence-based strategies to be developed by multiple stakeholders together. In addition, perceiving weight gain during the lockdown period may decrease the youths' frequency of ordering food to a larger extent, compared to those who perceived weight loss or no weight change. This implies that both the guidance on healthy diets and the regular call for attention to weight change would be needed to improve people's eating behaviors during the lockdown period due to health emergency.

Lockdown Impact on Food Ordering Patterns in China
Nevertheless, findings of this study should be treated with caution. First, the retrospective design may be subject to recall bias among the participants. Also, our participants formed a convenience sample that may not be perfectly representative of the Chinese youth, especially those who did not use smartphones or Internet media frequently. Second, the frequency of food ordering was collected using a specific questionnaire, so more information on the quantitative consumption data was not available, e.g., the average weekly frequency and time of food ordering were asked separately, which could not be linked to reveal more detailed patterns. Moreover, our study period fell into the period of spring festival, which may cause differences in food ordering and weight change to some extent through food storage. However, food storage due to the spring festival usually lasts 1-2 weeks, so we reasonably assume a limited impact of the spring festival on the food ordering patterns during the 11-week lockdown period. Third, to avoid the missing data issue, we did not distinguish different foods within the current major categories of food, such as noodles and dumplings, which might have different levels of calorie intake.

Despite the aforementioned limitations, this online survey using a snowball sampling method presented unique strengths by accumulating a large sample size in the targeted population promptly for drawing strong conclusions, which is of particular importance in the context of public health emergencies [30]. Also, in our online questionnaire, questions on each food ordering behavior before COVID-19 and under lockdown were placed next to each other for participants to better recall with comparison. With that said, although the survey results at each time point may be subject to recall bias on its own, differences in their answers at 2 time points should better reflect their lifestyle changes, at least, the perceived lifestyle changes which are usually highly correlated with their actual lifestyle changes. Also, we collected detailed information of food ordering patterns, including the frequency of eating, ordering time, and the types of foods ordered.

This timely large-scale study would help multiple stakeholders, including policy makers understand the status of young people's food ordering patterns and weight gain during the lockdown period, which may help them make decisions on providing feasible and targeted public health messages related to healthy food options and weight management [31]. Most schools in China, also in other countries, have adopted an online teaching mode for a long period due to COVID-19; hence, the po-

Obes Facts 2022;15:135-149 
tential long-term impact of the epidemic and mitigating strategies on youth's behaviors of food ordering and consumption warrant further research. It would also be interesting to examine differences in food ordering patterns between those going home to stay with their parents and staying on or close to campus in future vacations if still affected by COVID-19. The safety of ordered food, which used to be considered merely a potential concern by consumers, has now been more important than ever [32]. In this increasingly favored field, food safety should be more strictly regulated to ensure product quality. Also, although food ordering has decreased among the youth, their preferences seem to have changed toward high-sugar and -fat foods, which might be an important signal for unhealthy dietary behaviors because the youth may continue this habit after the end of the epidemic. From a perspective of public health, our results can provide evidence for public health policies in the post-lockdown period to decrease unhealthy food ordering. The increased weight status observed in youth during the COVID-19 epidemic might be present in other populations as well, which could bring challenges to public health. Therefore, more active guidance and publicity on fat and sugar control may be necessary to mitigate the impact of COVID-19 on public health. There is an urgent need to attract more people to eat healthy, and more attention should be paid to national nutrition and health education and targeted industry guidance. In addition to traditional ways to facilitate effective public health policies to guide people to adopt a healthier diet, nutritional guidance should also be incorporated into the online food ordering systems or, broadly, the digital channels from which people may order food. Globally, many countries have also been implementing similar measures for curbing the COVID-19, where all populations including the youth may also face similar challenges and hence could benefit from local governance on the basis of our timely findings.

\section{Acknowledgments}

We thank the International Institute of Spatial Lifecourse Epidemiology (ISLE) for research support.

\section{Statement of Ethics}

The study was approved by the Sichuan University Medical Ethical Review Board (KS2020414). An informed consent notice was highlighted on the front page of the questionnaire, and only those who agreed to participate and clicked the "agree" button were allowed to continue the questionnaire. Also, it has been stated on the cover page of the online questionnaire that the youth under 18 cannot proceed with the online survey without both parental consent and their assent.

\section{Conflict of Interest Statement}

The authors have no conflicts of interest to declare.

\section{Funding Sources}

This study was supported by Wuhan University. No funding sources have played any role in the preparation of data or the manuscript.

\section{Author Contributions}

S.Y., P.J., and C.Y. designed research; all authors conducted research; J.W., B.G., P.J., J.Z., and S.Y. analyzed data; S.Y., H.C., C.Y., and P.J. wrote the paper; P.J. and C.Y. had primary responsibility for final content. All authors read and approved the final manuscript.

\section{Data Availability Statement}

All data analyzed during this study could be available from the corresponding author, Prof. Peng Jia, upon reasonable request.

\section{References}

1 Liu W, Kang T-W. Research on the influence of $\mathrm{O} 2 \mathrm{O}$ take-out Chinese user satisfaction on continuous intention : the moderating effect of user habit; 2018.

2 Mayila M, Xueyin Z, Menghan J, Yuan R, Shankuan Z. How we eat determines what we become: opportunities and challenges brought by food delivery industry in a changing world in China. Eur J Clin Nutr. 2018; 72(9):1282-6.

3 Hong X. Food ordering service system design for chinese urban commuters based on internet of things; 2017.
4 Maimaiti M, Zhao X, Jia M, Ru Y, Zhu S. How we eat determines what we become: opportunities and challenges brought by food delivery industry in a changing world in China. Eur J Clin Nutr. 2018;72(9):1282-6.

5 Zhao X, Lin W, Cen S, Zhu H, Duan M, Li W, et al. The online-to-offline $(\mathrm{O} 2 \mathrm{O})$ food delivery industry and its recent development in China. Eur J Clin Nutr. 2021;75(2):232-7.

6 Zhu S. Development of nutritional studies in China. Eur J Clin Nutr. 2021;75(2):230-1. 
7 Jiang Y, Wang J, Wu S, Li N, Wang Y, Liu J, et al. Association between take-out food consumption and obesity among Chinese university students: a cross-sectional study. Int J Environ Res Public Health. 2019;16(6).

8 Gopinath B, Flood VM, Burlutsky G, Louie JC, Baur LA, Mitchell P. Frequency of takeaway food consumption and its association with major food group consumption, anthropometric measures and blood pressure during adolescence. Br J Nutr. 2016;115(11): 2025-30.

9 Smith KJ, Blizzard L, Mcnaughton SA, Gall SL, Dwyer T, Venn AJ. Takeaway food consumption and cardio-metabolic risk factors in young adults. Eur J Clin Nutr. 2012;66(5): 577-84.

10 Chinazzi M, Davis JT, Ajelli M, Gioannini C, Litvinova M, Merler S, et al. The effect of travel restrictions on the spread of the 2019 novel coronavirus (COVID-19) outbreak. Science. 2020:368.

11 Kraemer MUG, Yang CH, Gutierrez B, Wu $\mathrm{CH}$, Klein B, Pigott DM. The effect of human mobility and control measures on the COVID-19 epidemic in China. medRxiv. 2020: eabb4218.

12 Nguyen THD, Vu DC. Food delivery service during social distancing: proactively preventing or potentially spreading coronavirus disease-2019? Dis Med Pub Health Prepare. 2020:1-2.

13 Gates B. Responding to Covid-19: a once-ina-century pandemic? N Engl J Med. 2020; 382(18):1677-9.

14 Wang L, Wang Y, Ye D, Liu Q. Review of the 2019 novel coronavirus (SARS-CoV-2) based on current evidence. Int J Antimicrob Agents. 2020;55:105948.
15 Anderson RM, Heesterbeek H, Klinkenberg D, Hollingsworth TD. How will countrybased mitigation measures influence the course of the COVID-19 epidemic? Lancet. 2020;395(10228):931-4.

16 Remuzzi A, Remuzzi G. COVID-19 and Italy: what next? Lancet. 2020;395(10231):1225-8.

17 Huckle T, Parker K, Romeo JS, Casswell S. Online alcohol delivery is associated with heavier drinking during the first New Zealand COVID-19 pandemic restrictions. Drug Alcohol Rev. 2020.

18 Botelho LV, Cardoso LO, Canella DS. COVID-19 and the digital food environment in Brazil: reflections on the pandemic's influence on the use of food delivery apps. Cad Saude Publica. 2020;36(11):e00148020.

19 Poelman MP, Gillebaart M, Schlinkert C, Dijkstra SC, Derksen E, Mensink F, et al. Eating behavior and food purchases during the $\mathrm{CO}$ VID-19 lockdown: a cross-sectional study among adults in the Netherlands. Appetite. 2021;157:105002.

20 Jia P, Liu L, Xie X, Yuan C, Chen H, Guo B, et al. Changes in dietary patterns among youths in China during COVID-19 epidemic: the COVID-19 impact on lifestyle change survey (COINLICS). Appetite. 2021;158:105015.

21 Yang S, Guo B, Ao L, Yang C, Zhang L, Zhou $\mathrm{J}$, et al. Obesity and activity patterns before and during COVID-19 lockdown among youths in China. Clin Obes. 2020;10(6): e12416.

22 Zhou J, Xie X, Guo B, Pei R, Pei X, Yang S, et al. Impact of COVID-19 lockdown on physical activity among the chinese youths: the COVID-19 impact on lifestyle change survey (COINLICS). Front Public Health. 2021;9: 592795.

23 Luo M, Zhang D, Shen P, Yin Y, Yang S, Jia P. COVID-19 lockdown and social capital changes among youths in China. Int J Health Policy Manage. 2021.
24 Cole TJ, Lobstein T. Extended international (IOTF) body mass index cut-offs for thinness, overweight and obesity. Pediatr Obes. 2012; 7(4):284-94.

25 Jia P, Xue H, Zhang J, Wang Y. Time trend and demographic and geographic disparities in childhood obesity prevalence in China-evidence from twenty years of longitudinal data. Int J Environ Res Public Health. 2017;14(4): 369.

26 Duan S. The covid-19 outbreak: a Chinese school student's life in isolation for 73 days. BMJ Paediatr Open. 2020;4(1):e000699.

27 Peters MA, Green B, Mou C, Hollings S, Ogunniran MO, Rizvi F, et al. China's internationalized higher education during $\mathrm{Co}-$ vid-19: collective student autoethnography; 2020. p. 1-12.

28 Gregori D, Foltran F, Ghidina M, Berchialla P. Understanding the influence of the snack definition on the association between snacking and obesity: a review. Int J Food Sci Nutr. 2011;62(3):270-5.

29 Mediouni M, Madiouni R, Kaczor-Urbanowicz KE. COVID-19: how the quarantine could lead to the depreobesity. Obes Med. 2020;19: 100255 .

30 Cohen AB, Lee D, Long MD, Kappelman MD, Martin CF, Sandler RS, et al. Dietary patterns and self-reported associations of diet with symptoms of inflammatory bowel disease. Dig Dis Sci. 2013;58(5):1322-8.

31 Jia P. A changed research landscape of youth's obesogenic behaviours and environments in the post-COVID-19 era. Obesity Reviews. 2021;22(S1):e13162.

32 China prioritises food security amid COVID-19 outbreak. Emerald expert brief; 2020. 